\title{
The marathon of educational change
}

\author{
Dennis Shirley ${ }^{1} \cdot$ Anna Noble ${ }^{1}$
}

Published online: 6 May 2016

(C) Springer Science+Business Media Dordrecht 2016

If you'd like to feel optimistic about the future of educational change, consider adding The Second Machine Age: Work, Progress, and Prosperity in a Time of Brilliant Technologies (2014) by Erik Brynjolfsson and Andrew McAfee, to your reading list. The authors describe a spectacular future of "infinite computing" (p. 96) in which more and more things will be "free, perfect, and instant" (p. 168). Moore's law, predicting that technological progress will double in every year, will permanently destabilize old and now anachronistic bureaucracies, according to Brynjolfsson and McAfee. A golden age of human history awaits us.

Or does it? According to Yancy Toh's lead article in this issue of The Journal of Educational Change entitled "Leading Sustainable Educational Reform for Student-Centered Learning: A Complexity Perspective," dubious "infantile expectations" often infect too much thinking about technological change. In this investigation of decade-long technology integration in a Singapore primary school, Toh concludes that,

Piecemeal technology adoption efforts seldom result in deep changes. For integration to happen and thereafter be sustainable, the actors in the system must foster "ecological coherence"'. However, such coherence or alignment is transient as the conditions coalescing around technology, pedagogy and policies are constantly evolving. (p. 21)

In spite of everything that has been said and written, scholars and practitioners persist in believing that a single intervention-be it through innovative technology,

Dennis Shirley

Shirleyd@bc.edu

1 Lynch School of Education, Boston College, 140 Commonwealth Avenue, Campion Hall, Chestnut Hill, MA 02467-3813, USA 
curricular change, or just the right pedagogy—will lead all educators to a never entirely defined promised land.

Why do educators fall prey to such ideologies? According to the second article by Mamdouh Hassan and Benny Geys entitled "Expectations, Realizations and Approval of Tablet Computers in an Educational Setting," it may be that creating a sense of urgency and anticipation is a necessary lever to introduce educational change. Why would anyone bother to shift established practices unless it was out of a sense that times had changed, and that they must also? But in the case of technological change in Flanders, high expectations are correlated with educators' subsequent cynicism. Educational change is not an event, in this perspective, nor even a series of events. It is a long and demanding marathon. The authors explain that these findings indicate that policies should include provisions for managing the expectations of stakeholders:

$[\mathrm{O}]$ ne important policy recommendation from our analysis is that detailed and accurate information should be available about both benefits and difficulties related to introducing tablets in schools. This is likely to dampen unrealistically high expectations, and mitigate subsequent reward prediction error. (p.

Technological change, like all kinds of change, is difficult. Forget the simplistic bromides selling you on the wonders of technology or any other tool, Hassan and Geys tell us. Read authors like Brynjolffson and McAfee, so you understand the thinking of those who are driving the digital revolution, but don't get lost in the hyperbole. It's best to be honest with educators and to prepare everyone for a long, grueling ascent. Fabulous things may happen in labs but they don't translate easily to schools. Fortitude, not speed, is a new key virtue for educational change.

What does this mean for teachers, principals, students, and parents? In their article entitled "An International Review of 1:1 Computing in Schools," Sirajul Islam and Ake Grönlund argue that schools need to return to their core task of learning as the alpha and omega of change. Their literature review reveals that the oft-cited problem of technological distraction is a real one from the vantage point of teachers, although not necessarily of students. For the latter, computing offers highly desirable freedom, versatility, and communicability, such that the benefits that come along with new technologies outweigh the problems.

This only apparent dualism between teachers and students can be overcome, but two conditions must first be met. First, schools must overcome their custodial features to focus on deep, transformative learning. Second, students must be able to ignite and discipline their native curiosity in favor of the same learning agenda. In other words, all of the myriad factors that can should engage but sometimes distract educators and students from their core learning tasks-and this includes the kind of pedagogy, the nature of the curricula, and the forms of assessment-merit renewed scrutiny.

There is no escaping now the rapid advance of technology in all facets of our lives, from how we acquire groceries to how we process medical bills to how we communicate with family members and love ones. How these new technologies shall evolve to promote the core learning tasks of schools in the years to come is not 
revealed by the authors. Still, the message is clear: don't ask new technologies to advance deep learning simply by placing them in front of students. Indeed the authors find that, "Using technology in the classroom can go either way; student results can improve or deteriorate. Only good pedagogy guarantees improvements" (p. 26).

"A New Model of Educational Innovation: Exploring the Nexus of Organizational Learning, Distributed Leadership, and Digital Technologies" by Marleen Rikkerink and her colleagues in Holland describes how two teams of teachers responded in different ways to technological reforms. When change is adopted voluntarily, leadership is distributed, and technology is brought in as a supplement to good pedagogy, teachers are not only willing, but eager to innovate. When change is forced upon educators, leadership is reified, and technology is sold as a panacea, resistance sets in. Ultimately the authors find that " $[\mathrm{A}] \mathrm{n}$ increased understanding of the relation between distributed leadership and collective sensemaking as an important prerequisite for the incorporation of digital learning materials in teaching practice" (p. 21). Calling for "context-conscious leadership," the authors blend fine, empirically grounded research with provocative theorybuilding.

How change is introduced, led, adjusted, and evaluated has profound effects, then, on the working conditions of educators. The findings from this research offers an implicit rebuke to those reformers who advance their agendas without due consideration for either the rights or the needs of those who are tasked with implementing change. In many cases, critics direct their attention to governments that have pushed through reforms with a single-minded intensity that framed those most directly impacted by the reforms as either passive bystanders or mindless implementers. But this is too easy. In some cases, the research community itself has expressed disdain for the lowly and beleaguered classroom teachers. Those who have to bear the brunt of recent reforms have also had to deal with their scorn. It's a recipe for stalled reforms and little learning.

In their article, William Penuel and his colleagues describe current efforts in the US to overcome the punitive sanctions of the No Child Left Behind Act to structure learning exchanges between researchers and practitioners into long-term relationships of sustained interaction. "Enhancing Use of Learning Science Research in Planning for and Supporting Educational Change: Leveraging and Building Social Networks" indicates that the theory-practice divide decried by educators for generations has a structural and cultural antidote.

We need continual, iterative, dialogue and debate between educators and the research community, not as a one-off symposium but as a whole professional, and indeed existential, way of being in the world.

Students have suffered too long when adults have been at loggerheads about the best ways to improve teaching and learning. Their learning requires united professionals who overcome their myriad differences to forge deep and long-term relationships with one another. If we can forge such partnerships and institutionalize them so that they endure over time, we will be able to enact new kinds of professional communities that both uplift the prosaic everyday talents of classroom 
teachers and also bring them into generative relationships with the research community.

But be forewarned: This isn't a sprint, and it's not for the faint-hearted. Real educational change requires stamina and perseverance. Read the accounts of technological utopians, but don't be deluded. Resistance to change should be anticipated and planned for. This is what makes education a calling that requires dedicated professionals who will stay with the hard tasks of school improvement over decades. This is what makes it a marathon of educational change.

\section{Reference}

Brynjolfsson, E., \& McAfee, A. (2014). The second machine age: Work, progress, and prosperity in a time of brilliant technologies. New York: Norton. 